\title{
Body Composition in Preterm Infants Who Are Fed Long-Chain Polyunsaturated Fatty Acids: A Prospective, Randomized, Controlled Trial
}

\author{
SHARON GROH-WARGO, JOAN JACOBS, NANCY AUESTAD, DEBORAH L. O'CONNOR, \\ JOHN J. MOORE, AND EDITH LERNER
}

Departments of Pediatrics [S.G.-W., J.J.M.], Nutrition [S.G.-W., E.L.], and Reproductive Biology [J.J.M.], Case Western Reserve University School of Medicine, Cleveland, Ohio 44109; Ross Products Division

[J.J., N.A.], Abbott Laboratories, Columbus, Ohio 43215; and University of Toronto and The Hospital for Sick Children [D.L.O.], Toronto, Ontario, Canada, M5G 1 X8

\begin{abstract}
The objective of this study was to evaluate growth and body composition of premature infants who were fed formulas with arachidonic acid (ARA; 20:4n6) and docosahexaenoic acid (DHA; 22:6n3) to 1 y of gestation-corrected age (CA). Preterm infants (750-1800 $\mathrm{g}$ birth weight and $<33$ wk gestational age) were assigned within $72 \mathrm{~h}$ of first enteral feeding to one of three formulas: control $(n=22)$, DHA+ARA from fish/fungal oil [DHA+ARA(FF); $n=20]$, or DHA+ARA from egg/fish oil [DHA + ARA(EF); $n=18]$. Human milk feeding was allowed on the basis of the mother's choice. Infants were fed breast milk and/or preterm formulas with or without $0.26 \%$ DHA and $0.42 \%$ ARA to term CA followed by breast milk or postdischarge preterm formulas with or without $0.16 \%$ DHA and $0.42 \%$ ARA to 12 mo CA. Body composition was measured by dual-energy $\mathrm{x}$-ray absorptiometry. There were no significant differences among the three study groups at any time point in weight, length, or head circumference. Bone mineral content and bone mineral density did not differ among groups. At 12 mo CA, infants who were fed DHA+ARA-supplemented formulas had significantly greater lean body mass $(p<0.05)$ and significantly less fat mass
\end{abstract}

\section{ABSTRACT}

$(p<0.05)$ than infants who were fed the unsupplemented control formula. The DHA+ARA-supplemented formulas supported normal growth and bone mineralization in premature infants who were born at $<33$ wk gestation. Preterm formulas that had $\mathrm{DHA}+\mathrm{ARA}$ at the levels and ratios in this study and were fed to 1 y CA led to increased lean body mass and reduced fat mass by 1 y of age. (Pediatr Res 57: 712-718, 2005)
ARA, arachidonic acid

\section{Abbreviations}
CA, corrected age
DEXA, dual-energy x-ray absorptiometry
DHA, docosahexaenoic acid
EF, egg-derived triglyceride/fish oil
EPA, eicosapentaenoic acid
FF, fish/fungal oil
NEC, necrotizing enterocolitis
PC, phosphatidylcholine
PE, phosphatidylethanolamine
PGE2, prostaglandin E2

The long-chain polyunsaturated fatty acids docosahexaenoic acid (DHA; 22:6n-3) and arachidonic acid (ARA; 20:4n-6) are currently added to infant formulas in many countries. ARA and DHA are the predominant n- 6 and n-3 long-chain polyunsaturated fatty acids in the CNS, and it has been postulated that an adequate dietary supply during infancy is necessary to support optimum neurodevelopment (1). The results of several investigations indicate that visual acuity and neurocognitive devel-

Received May 26, 2004; accepted September 22, 2004

Correspondence: Sharon Groh-Wargo, Ph.D., Case Western Reserve University, School of Medicine, Department of Pediatrics, Departments of Pediatrics and Nutrition, R240 MetroHealth Medical Center, 2500 MetroHealth Drive, Cleveland, OH 44109; e-mail: sgrohwargo@metrohealth.org.

This work was supported, in part, by NIH General Clinical Research Center (GCRC) Grant \#MO1-RR00080, and by a grant from Ross Products Division, Abbott Laboratories.

DOI: 10.1203/01.PDR.0000156509.29310.55 opment are enhanced in preterm infants who are fed formulas that are supplemented with DHA or both ARA and DHA (2-5). Most $(4,6-8)$ but not all (9) studies have reported normal growth in preterm infants who were fed formulas that were supplemented with both ARA and DHA.

The long-chain n-6 (ARA) and n-3 [DHA and eicosapentaenoic acid (EPA; 20:5n-3)] fatty acids are important biomediators that can affect growth and body composition through diverse mechanisms. The level and the ratio of these fatty acids can influence cell membrane properties, cell-to-cell signaling processes, the expression of genes that regulate cell differentiation and growth, and the synthesis of eicosanoids that affect bone metabolism (10). Animal studies suggest that dietary n-6 and n-3 fatty acids can affect both fat mass and distribution $(11,12)$ and bone metabolism $(13,14)$. 
There is limited information regarding the effects of the dietary long-chain n- 6 and n-3 fatty acids on body composition in humans. In the present study, growth and body composition were investigated in preterm infants who were fed formulas that were supplemented with ARA and DHA from first enteral formula feedings to $1 \mathrm{y}$ term corrected age (CA).

\section{METHODS}

Study design. This controlled, double-blind, randomized study was designed to evaluate body composition in premature infants who were fed one of two formulas with different sources of DHA and ARA (DHA+ARA) or a control formula with no added DHA or ARA to 12 mo CA. Assessments were made at the time enteral feedings were begun (study day 1), at 35 and $40 \mathrm{wk}$ $\mathrm{CA}$ (term), and at 4 and $12 \mathrm{mo}$ CA. Study formulas were $24 \mathrm{kcal} / \mathrm{fl} \mathrm{oz}$ preterm infant formulas from study day 1 to $40 \mathrm{wk} \mathrm{CA}$ and $22 \mathrm{kcal} / \mathrm{fl}$ oz postdischarge formulas from 40 wk CA to 12 mo CA.

This protocol was approved by the Institutional Review Board for Research Involving Human Subjects at the MetroHealth Medical Center. Written informed consent was obtained from parents of each subject before study enrollment.

Subjects. Sixty preterm infants with birth weights from 750 to $1800 \mathrm{~g}$ and gestational age at birth $<33$ wk were recruited between September 1997 and September 1998 from the neonatal intensive care unit at MetroHealth Medical Center (Cleveland, $\mathrm{OH}$ ). Twenty of the 60 subjects were also enrolled in a larger, multicenter study (4). Infants were enrolled within $72 \mathrm{~h}$ of the first enteral feeding and could be enrolled as long as enteral feeding was initiated by the 28th day of life. Infants with one or more of the following conditions before randomization were excluded: congenital abnormalities that could affect growth or development, major surgery, periventricular hemorrhage greater than grade II (Papile classification) (15), asphyxia resulting in severe and permanent neurologic damage, treatment with extracorporeal membrane oxygenation, maternal incapacity (including substance abuse), or uncontrolled systemic infection at the time of enrollment. There were no restrictions on the type of feeding before study entry

The randomization schedule was stratified by sex and birth weight group $(750-1250 \mathrm{~g}$ and $1251-1800 \mathrm{~g})$. When twins were enrolled, both twins were assigned to the same formula group.

Study feedings. Study formulas were those described previously (4) Briefly, preterm infants who received formula were fed $24 \mathrm{kcal} / \mathrm{fl}$ oz Similac Special Care that contained DHA $(0.26 \%)$ and ARA $(0.42 \%)$ either from fungal oil and fish oil [DHA + ARA(FF)] or from egg-derived triglyceride and fish oil [DHA + ARA(EF)] from the first enteral formula feeding until $40 \mathrm{wk}$ CA. Infants in the control group (control) were fed $24 \mathrm{kcal} / \mathrm{fl}$ oz Similac Special Care. At $40 \mathrm{wk}$ CA, infants were transitioned to $22 \mathrm{kcal} / \mathrm{fl}$ oz NeoSure (control) or to NeoSure with DHA $(0.16 \%)$ and ARA $(0.42 \%)$ from the same sources that were fed previously except that no fish oil was added to NeoSure in the DHA+ARA(EF) feeding group. The fatty acid composition of the formulas is in Table 1. At present, commercially available Similac Special
Care Advance contains $0.25 \%$ DHA and 0.40\% ARA, and Similac NeoSure Advance contains $0.15 \%$ DHA and $0.40 \%$ ARA.

Breast feeding was encouraged before initiating formula feeding and throughout the entire study for infants in each group. Breast milk was provided as expressed milk fed by tube or bottle or by nursing at the breast. When the amount of milk produced by the mother was insufficient to meet the volume and energy needs of the infant, the randomly assigned study formula was used to make up the shortfall. During the initial hospital stay, it was recommended that expressed breast milk be fortified to achieve an energy density of 22-24 $\mathrm{kcal} / \mathrm{fl} \mathrm{oz}$. Infants were categorized as exclusively formula-fed or as receiving mixed formula-breast milk feedings. Exclusive formula feeding was defined as less than a total of $100 \mathrm{~mL} / \mathrm{kg}$ birth weight of in-hospital breast milk intake $(\sim 130 \mathrm{~mL})$ and formula for $>80 \%$ of feedings at term CA. All other infants were placed in the formula plus breast milk group.

Feeding procedures. Study day 1 was the day the infant was randomized and began enteral feeding of the assigned study formula or breast milk. In-hospital, parenteral nutrition was administered to infants who could not tolerate full enteral feeding. A daily record was kept of the volume of study formula and breast milk provided. The use of supplemental multivitamins and/or minerals was permitted as indicated by the attending physician. Enteral feedings were withheld at the discretion of the attending physician when the infant showed signs of intolerance to the formula and were reintroduced after indicators of intolerance resolved. When radiographic evidence of necrotizing enterocolitis (NEC) occurred or when NEC was documented at surgery, the subject was removed from the study.

Infants were fed the $24 \mathrm{kcal} / \mathrm{fl}$ oz study feedings from study day 1 to $40 \mathrm{wk}$ $\mathrm{CA}$ and $22 \mathrm{kcal} / \mathrm{fl}$ oz study feedings from $40 \mathrm{wk} \mathrm{CA}$ to $12 \mathrm{mo} \mathrm{CA}$. For three consecutive days before the 40-wk CA, 4-mo CA, and 12-mo CA assessments, parents kept diaries to record formula intake and the frequency of breastfeeding. Parents were encouraged to delay the introduction of solid foods until infants were at least 2 mo CA.

Anthropometric data. Birth weight, length, and head circumference measurements were obtained from the medical record. In-hospital, weights were measured daily, and length and head circumference were measured weekly using standardized procedures (16). Postdischarge weight, length, and head circumference were recorded at 35 and $40 \mathrm{wk} \mathrm{CA}$ and at 4 and 12 mo CA. Approximately $25 \%$ of the 35 -wk CA visits, $94 \%$ of the 40 -wk CA visits, and $100 \%$ of the 4- and 12-mo CA visits were postdischarge. At each assessment, weight measurements were obtained once (in hospital) or twice (postdischarge). Recumbent length and head circumferences were obtained twice. When the two measurements were not within a specified range (weight $\pm 10 \mathrm{~g}$ and length and head circumference $\pm 0.5 \mathrm{~cm}$ ), a third measurement was taken. Multiple measurements were averaged for statistical analyses. Infants were weighed nude in-hospital and after hospital discharge using calibrated digital electronic scales (Olympia Smart Scales, Olympia Medical Systems, Seattle, WA; and Scale Tronix, Wheaton, IL, respectively). Lengths were measured using a standard-length board sized for either preterm or term infants (Ellard Instrumentation, Seattle, WA). Head circumferences were measured using the Ross Laboratories INSER-TAPE ${ }^{\circledR}$.

Dual energy $x$-ray absorptiometry. Dual energy $\mathrm{x}$-ray absorptiometry (DEXA) measurements were made with a whole-body scanner (Hologic QDR

Table 1. Fatty acid composition of study formulas

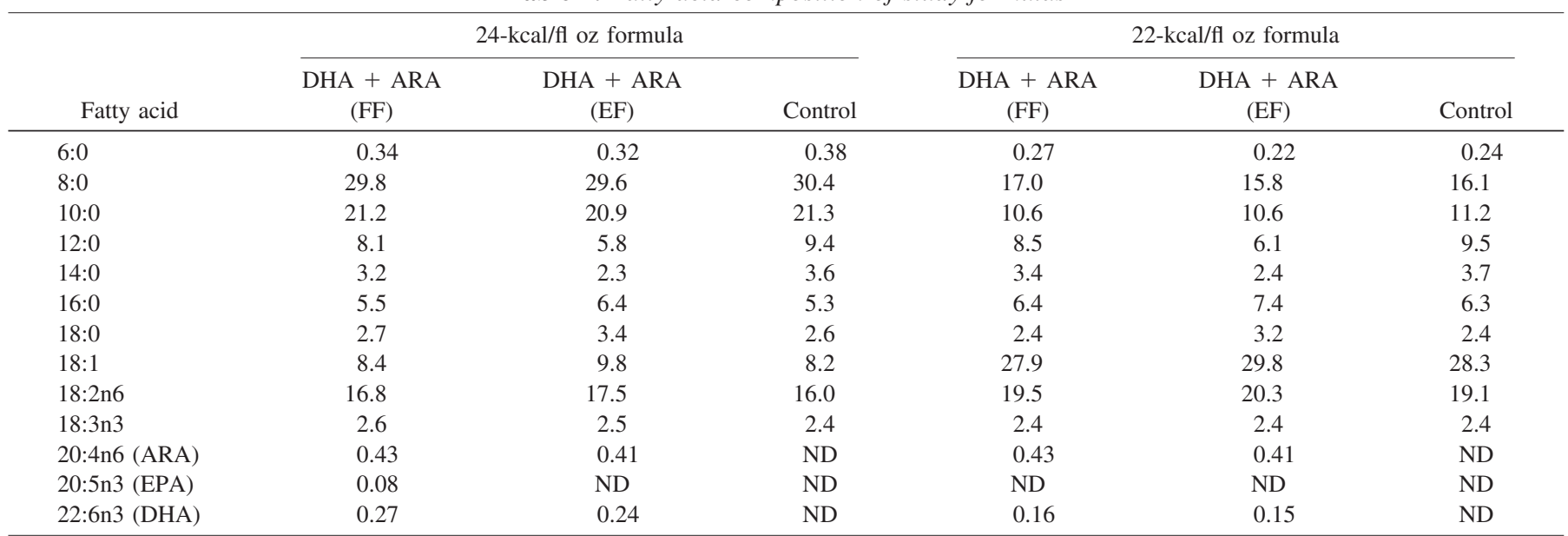

ND, none detected. Values are mean (g/100 g) of total fatty acids. Fatty acid levels were determined by Analytical Research and Services, Ross Products Division, Abbott Laboratories, (Columbus, $\mathrm{OH}$ ). 
2000/W Densitometer, Infant Whole Body Software Version 5.71P; Hologic, Bedford, MA) operated in the single-beam mode. All DEXA technicians had completed certification to operate the densitometer. Quality control scans using the manufacturer-supplied step-phantom were performed according to hospital protocol. Measurements of total body bone mineral content ( $\mathrm{g}$ ), total body bone mineral density $\left(\mathrm{g} / \mathrm{cm}^{2}\right)$, total body fat $(\mathrm{kg})$, and total lean mass $(\mathrm{kg})$ were made at 35 and 40 wk CA and at 4 and 12 mo CA. Infants wore only disposable diapers, were swaddled in a blanket or a sheet, and were placed on a blanket on top of the pediatric platform and next to the step-phantom block, both supplied by the manufacturer. Infants were near sleep or fully asleep before scanning was started. No sedation was used. Scanning was continued until a complete scan that included no more than three visible partial breaks or not more than one complete break on the image was obtained or until it became clear that the infant was unable to lie still for a sufficient period of time. One hour was used as the approximate maximum time to attempt completion of one usable scan. Coefficients of variation of repeated DEXA measurement with similar equipment and software as used in the present study are reported to be $\sim 5 \%(17,18)$. The average radiation dose of one infant whole-body scan is estimated at $3 \mu \mathrm{Sv}$ ( $0.3 \mathrm{mrem})$. Bone mineral content (g) was sensitive to 0.01 , bone mineral density $\left(\mathrm{g} / \mathrm{cm}^{2}\right)$ was sensitive to 0.001 , and body fat and lean mass were sensitive to $0.1 \mathrm{~g}$.

Blood fatty acid analyses. Blood was collected by venipuncture at the 4 and 12-mo CA visits for determination of the fatty acid composition of plasma and of the phosphatidylcholine (PC) and phosphatidylethanolamine (PE) membrane fractions of erythrocytes. Blood samples were processed and frozen at $-70^{\circ} \mathrm{C}$ and shipped on dry ice to a central laboratory (Analytical Research and Services, Ross Products Division, Columbus, OH) for analysis (19).

Statistical analyses. The estimated sample size was targeted to detect a 0.5 -SD difference in fat-free mass with $80 \%$ power using a two-sided 0.05 level test. Preterm infants who were fed formulas with and without supplemental DHA and who had their fat-free mass measured at 4 mo CA were used to estimate variability (20). Formula assignment was determined using a computer-generated randomization schedule based on a permuted blocks algorithm. Categorical demographic variables were evaluated using $\chi^{2}$ tests of association and Fisher exact tests, whereas continuous demographic variables were evaluated using analysis of covariance (ANCOVA). Model fit was assessed using residual and stem-leaf plots for all parametric analyses of continuous variables.

Anthropometric and body composition data were assessed both by visit using ANCOVA and longitudinally using repeated measures analyses. The analysis of anthropometric measures included study feeding group, visit, sex, birth weight, mixed versus exclusive formula feeding, and interactions between study feeding group and visit as terms in the model. The analysis of body composition measures included study feeding group, visit, sex, race, body weight at scan, mixed versus exclusive formula feeding, and interactions between study feeding group and visit as terms in the model. When the tests of interaction between feeding group and visit were significant, pair-wise comparisons among the three feeding groups were performed for that visit.

Change in bone mineral content between study visits was assessed for the following five intervals: $35-40 \mathrm{wk} \mathrm{CA}, 4 \mathrm{mo}, 12 \mathrm{mo} C A$, and $40 \mathrm{wk}$ to $4 \mathrm{mo}$ and 12 mo CA. The ANCOVA model included terms for study feeding group, sex, mixed versus exclusive formula feeding, race, and average body weight between DEXA measurements.

All hypothesis testing was two-sided at the 5\% level for main effects and at the $15 \%$ level for interaction tests. Post hoc pair-wise comparisons following significant interaction tests were done using $t$ tests for differences between least-squares (LS) means (group means adjusted for the other terms in the analysis model). No adjustments were made for multiplicity of endpoints tested in this study. All analyses were done using either PC SAS ${ }^{\circledR}$ version 8.02 (PROC MIXED, PROC GLM, PROC FREQ, and PROC UNIVARIATE) or StatView ${ }^{\circledR}$ version 5.1.

\section{RESULTS}

Sixty infants were randomized. One infant who received a diagnosis of a rare neurologic disorder and two infants who were breast-fed exclusively throughout the study were excluded from the analyses. Birth anthropometrics, gestational age, sex, race, percentage of infants with birth weight appropriate for gestational age, postnatal age at study day 1, percentage of infants in each birth weight group, 5-min Apgar scores, and amount of breast milk intake did not differ among study groups (Table 2). The frequency of breast milk feedings was not significantly different among the three groups. At 40 wk CA, 44, 17, and $24 \%$ of infants in the DHA+ARA(EF), $\mathrm{DHA}+\mathrm{ARA}(\mathrm{FF})$, and control groups, respectively, consumed breast milk at least once a day. By 4 mo CA, only 17, 6, and $5 \%$ of infants in the DHA+ARA(EF), DHA + ARA(FF), and control groups, respectively, consumed any breast milk. There were significantly more twin births in the DHA+ARA(EF) group compared with the DHA+ ARA(FF) and control groups.

Table 2. Characteristics of preterm infants who were fed formulas with DHA and ARA or unsupplemented control formulas

\begin{tabular}{|c|c|c|c|c|}
\hline & DHA + ARA (FF) & $\mathrm{DHA}+\mathrm{ARA}(\mathrm{EF})$ & Control & $p$ value* \\
\hline Sample size $(n)$ & 18 & 18 & 21 & \\
\hline Birth weight $(\mathrm{g})$ & $1424 \pm 78$ & $1363 \pm 57$ & $1322 \pm 59$ & 0.495 \\
\hline Birth length (cm) & $39.1 \pm 0.8$ & $39.6 \pm 0.6$ & $38.3 \pm 0.6$ & 0.373 \\
\hline Gestational age (wk) & $30.6 \pm 0.6$ & $30.4 \pm 0.5$ & $30.0 \pm 0.5$ & 0.695 \\
\hline Postnatal age at study day 1 & $5.7 \pm 0.9$ & $3.7 \pm 0.9$ & $5.5 \pm 0.9$ & 0.190 \\
\hline Ethnicity [\% (n)] & & & & 0.190 \\
\hline Gender $[\%(n)]$ & & & & 0.547 \\
\hline Male & $44(8)$ & $56(10)$ & $62(13)$ & \\
\hline Multiple birth status $[\%(n)]$ & & & & $0.046 \dagger$ \\
\hline Singleton & $72(13)^{\mathrm{a}}$ & $44(8)^{\mathrm{b}}$ & $81(17)^{\mathrm{a}}$ & \\
\hline Twin & $28(5)$ & $56(10)$ & $19(4)$ & \\
\hline Size at birth $[\%(n)]$ & & & & 0.093 \\
\hline Feeding category $[\%(n)]$ & & & & 0.352 \\
\hline Exclusive formula & $50(9)$ & $72(13)$ & $67(14)$ & \\
\hline Formula plus breast milk & $50(9)$ & $28(5)$ & $33(7)$ & \\
\hline
\end{tabular}

Data are the mean \pm SEM (number of subjects) unless otherwise indicated. AGA, appropriate for gestational age; SGA, small for gestational age.

* ANOVA, $\chi^{2}$, or Fisher exact test.

$\dagger$ Different letters in the same row indicate significant pair-wise differences among groups. 
The numbers of analyzable subjects at study day 1,35-wk CA, 40-wk CA, 4-mo CA, and 12-mo CA visits were 57, 55, 53, 45, and 41, respectively. Sixteen subjects dropped out of the study between study day 1 and the 12-mo CA visit. The reasons for early exit included switching to a nonstudy formula per physician recommendation [control, $n=7$; DHA $+\mathrm{ARA}(\mathrm{FF}), n=$ 0 ; DHA $+\mathrm{ARA}(\mathrm{EF}), n=1]$, voluntary withdrawal by parent or investigator [control, $n=0 ; \mathrm{DHA}+\mathrm{ARA}(\mathrm{FF}), n=0$; $\mathrm{DHA}+\mathrm{ARA}(\mathrm{EF}), n=2]$, noncompliance with study visits [control, $n=0$; DHA+ARA(FF), $n=3$; DHA+ARA(EF), $n=2$ ], and death unrelated to study participation [control, $n=$ 0 ; $\mathrm{DHA}+\mathrm{ARA}(\mathrm{FF}), n=1$; DHA + ARA(EF), $n=0]$.

Postnatal ages at each study time point were not significantly different among the three groups (data not shown). Estimated enteral energy intakes from formula were not significantly different among the three groups. From study day 1 to hospital discharge and at $40 \mathrm{wk}, 4 \mathrm{mo}$, and $12 \mathrm{mo}$ CA, enteral energy intakes $\left(\mathrm{kcal} \cdot \mathrm{kg}^{-1} \cdot \mathrm{d}^{-1} \cdot\right)$ for the DHA+ARA(FF), $\mathrm{DHA}+\mathrm{ARA}(\mathrm{EF})$, and control groups were, respectively, $93 \pm$ $11,99 \pm 9$, and $95 \pm 3(p=0.910) ; 120 \pm 8,120 \pm 17$, and $116 \pm 6(p=0.968) ; 100 \pm 7,107 \pm 19$, and $114 \pm 12(p=$ $0.764)$; and $71 \pm 11,88 \pm 14$, and $67 \pm 7(p=0.354)$.

Development of significant clinical complications was noted during the hospital stay, including patent ductus arteriosus (medication and/or surgical treatment), bronchopulmonary dysplasia (supplemental oxygen beyond 1 mo postnatal or 36 wk CA), or intraventricular hemorrhage (greater than or equal to grade II). No differences in the percentage of infants with patent ductus arteriosus, bronchopulmonary dysplasia, or an intraventricular hemorrhage greater than grade II were found: $22.2,22.2$, and $33.3 \%$ for infants in the DHA+ARA(FF), $\mathrm{DHA}+\mathrm{ARA}(\mathrm{EF})$, and control groups, respectively $(p=$ 0.656). No infants developed confirmed NEC.

ARA and DHA in plasma and erythrocytes. Plasma levels of ARA and DHA were significantly lower in the control versus the experimental groups. At 4 mo CA, plasma levels of ARA (wt\%) for the DHA+ARA(FF), DHA+ARA(EF), and control groups were, respectively, $12.0 \pm 0.5,12.0 \pm 0.6$, and $8.6 \pm 0.9(p<0.01)$ and at 12 mo CA were $13.2 \pm 1.1,12.5$ \pm 0.6 , and $9.6 \pm 0.8(p<0.01)$. At 4 mo CA, plasma levels of DHA (wt \%) for the DHA+ARA(FF), DHA+ARA(EF), and control groups were, respectively, $3.4 \pm 0.1,3.2 \pm 0.2$, and 1.8 $\pm 0.2(p<0.001)$ and at 12 mo CA were $3.8 \pm 0.3,3.5 \pm 0.2$, and $1.8 \pm 0.2(p<0.001)$. At 12 mo CA, erythrocyte PE and PC DHA levels were significantly lower in the control versus the experimental groups $(p<0.04)$. Throughout the study, there were no significant differences in erythrocyte PE and PC ARA levels among the three study groups (data not shown).

Growth and body composition. There were no significant differences among the three study groups in the longitudinal analyses of weight, length, or head circumference (Table 3). There were no significant differences among the three study groups in bone mineral density or bone mineral content (Table 4). There were no significant differences among the groups for rate of bone mineral content gain between any interval measured. For example, increase in bone mineral content $(\mathrm{g} / \mathrm{d})$ for the DHA+ARA(FF), DHA+ARA(EF), and control groups from 35 to 40 wk CA was $0.54 \pm 0.05,0.52 \pm 0.05$, and $0.58 \pm 0.05$, respectively; from $40 \mathrm{wk}$ to $4 \mathrm{mo}$ CA was $0.63 \pm$ $0.03,0.70 \pm 0.05$, and $0.66 \pm 0.04$, respectively; and from 40 wk to 12 mo CA was $0.38 \pm 0.03,0.40 \pm 0.04$, and $0.43 \pm$ 0.03 , respectively. Similarly, there were no significant differences among the groups for rate of bone mineral content gain in any interval measured (data not shown).

At the 12-mo CA visit, there were significant differences in lean body mass and fat mass between the infants who were fed the DHA+ARA-supplemented formulas compared with the infants who were fed the unsupplemented control formulas. The LS adjusted means ( \pm SEM) at 12 mo CA for lean body mass $(\mathrm{kg})$ were greater for infants in the DHA+ARA(FF)

Table 3. Weight, length, and head circumference of preterm infants who were fed formulas with DHA and ARA or unsupplemented control formulas

\begin{tabular}{|c|c|c|c|}
\hline & $\begin{array}{c}\text { DHA + ARA } \\
(\mathrm{FF})\end{array}$ & $\begin{array}{c}\text { DHA + ARA } \\
\text { (EF) }\end{array}$ & Control \\
\hline \multicolumn{4}{|l|}{ Weight $(\mathrm{g})$} \\
\hline Study day 1 & $1349 \pm 76(18)$ & $1259 \pm 57(18)$ & $1230 \pm 63(21)$ \\
\hline 40 wk CA & $3147 \pm 149(18)$ & $3136 \pm 105(17)$ & $3280 \pm 135(18)$ \\
\hline $4 \mathrm{mo} \mathrm{CA}$ & $6154 \pm 212(16)$ & $6432 \pm 217(14)$ & $6524 \pm 220(14)$ \\
\hline 12 mo CA & $8977 \pm 293$ & $9505 \pm 243(13)$ & $9343 \pm 307(14)$ \\
\hline 35 wk CA & $42.7 \pm 0.7(17)$ & $42.7 \pm 0.5(18)$ & $42.5 \pm 0.5(18)$ \\
\hline 40 wk CA & $48.2 \pm 0.7(18)$ & $48.1 \pm 0.5(17)$ & $48.0 \pm 0.7(18)$ \\
\hline $4 \mathrm{mo} \mathrm{CA}$ & $60.9 \pm 0.6(16)$ & $62.8 \pm 0.7(14)$ & $61.8 \pm 0.7(14)$ \\
\hline $12 \mathrm{mo} \mathrm{CA}$ & $75.2 \pm 0.9(14)$ & $76.3 \pm 0.8(13)$ & $73.9 \pm 0.9(14)$ \\
\hline \multicolumn{4}{|c|}{ Head circumference $(\mathrm{cm})$} \\
\hline Study day 1 & $27.0 \pm 0.9(7)$ & $28.4 \pm 0.4(9)$ & $26.4 \pm 0.6(8)$ \\
\hline
\end{tabular}

Data are reported as the unadjusted mean \pm SEM (number of subjects). Differences among groups were determined using repeated measures ANCOVA controlling for visit, sex, breast milk intake, birth weight, and feeding group-by-visit interactions. No significant study feeding group differences $(p>0.05)$ were found. 
Table 4. Bone mineral density and bone mineral content in preterm infants who were fed formulas with DHA and ARA or unsupplemented control formulas at 35 and $40 \mathrm{wk} C A$ and 4 and $12 \mathrm{mo} C A$

\begin{tabular}{lccc}
\hline & DHA + ARA (FF) & DHA + ARA (EF) & Control \\
\hline Bone mineral density $\left(\mathrm{g} / \mathrm{cm}^{2}\right)^{*}$ & & & \\
35 wk CA & $0.145 \pm 0.004(17)$ & $0.146 \pm 0.004(18)$ & $0.140 \pm 0.004(18)$ \\
40 wk CA & $0.170 \pm 0.005(18)$ & $0.165 \pm 0.004(17)$ & $0.172 \pm 0.005(17)$ \\
4 mo CA & $0.257 \pm 0.006(15)$ & $0.258 \pm 0.007(12)$ & $0.263 \pm 0.008(12)$ \\
12 mo CA & $0.323 \pm 0.010(12)$ & $0.324 \pm 0.008(11)$ & $0.333 \pm 0.009(10)$ \\
Bone mineral content $(\mathrm{g})^{*}$ & $28.8 \pm 1.9(17)$ & $28.1 \pm 1.6(18)$ & $26.8 \pm 1.5(18)$ \\
35 wk CA & $49.6 \pm 3.1(18)$ & $46.2 \pm 2.3(17)$ & $49.4 \pm 3.2(17)$ \\
40 wk CA & $130.5 \pm 6.4(15)$ & $136.4 \pm 6.7(12)$ & $132.2 \pm 5.0(12)$ \\
4 mo CA & $226.2 \pm 10.5(12)$ & $234.0 \pm 7.4(12)$ & $239.4 \pm 10.3(10)$ \\
12 mo CA &
\end{tabular}

Data are reported as the unadjusted mean \pm SEM (number of subjects). Differences among groups were determined using repeated measures ANCOVA controlling for visit, body weight at study visit, sex, race, breast milk intake, and feeding group-by-visit interactions.

* Not significant.

$(6.83 \pm 0.13)$ and the DHA+ARA(EF) $(7.00 \pm 0.14)$ groups than in the control $(6.53 \pm 0.15)$ group and for fat mass $(\mathrm{kg})$ were less for infants in the DHA+ARA(FF) $(2.60 \pm 0.12)$ and the DHA+ARA(EF) $(2.60 \pm 0.13)$ groups than in the control (3.07 \pm 0.14$)$ group $(p<0.05$; Fig. 1$)$. These differences were confirmed by the repeated measures analysis.

\section{DISCUSSION}

Very low birth weight infants are commonly discharged from the hospital on nutrient-enriched feedings. Twenty-two$\mathrm{kcal} / \mathrm{oz}$ formulas, such as those used in the present study, are increasingly prescribed. Several studies reported that postdischarge nutrient-enriched feedings are associated with significant improvements in catch-up growth (21-23) and may be particularly advantageous for boys and for infants with the lowest birth weights $(21,22)$. Short-term feeding of preterm formulas is not associated with changes in plasma mineral concentration (24), but feeding of nutrient-enriched formulas
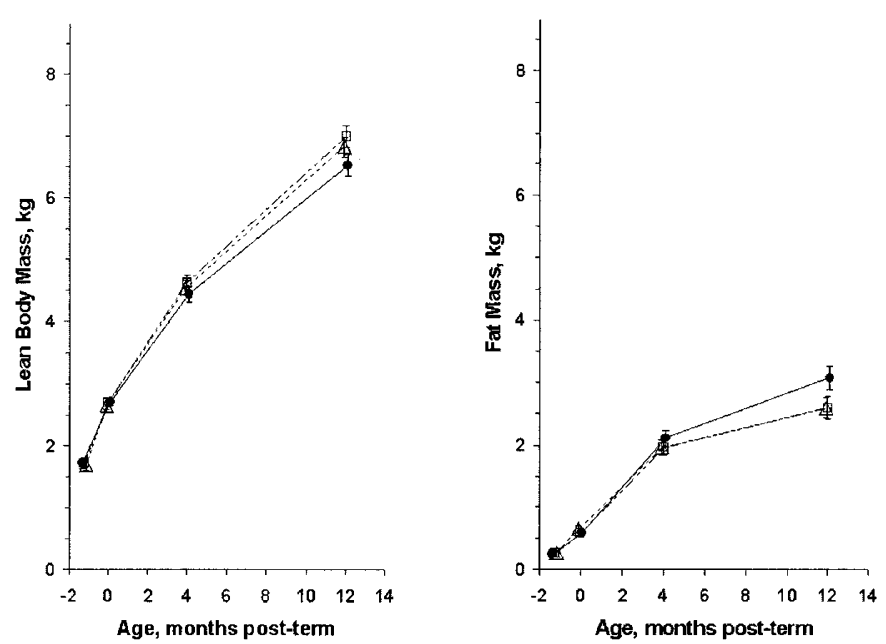

Figure 1. Lean body mass and fat mass at 35 and $40 \mathrm{wk} \mathrm{CA}$ and at 4 and 12 mo CA in preterm infants who were fed formulas with DHA and ARA or unsupplemented control formulas. Data points represent LS means adjusted for sex, race, body weight, and breast milk intake. At 12 mo, lean body mass was significantly greater and fat mass was significantly less in infants who were fed formulas that were supplemented with DHA and ARA with either the $\mathrm{DHA}+\mathrm{ARA}(\mathrm{FF})(\triangle ; n=12)$ or $\mathrm{DHA}+\mathrm{ARA}(\mathrm{EF})(\square ; n=12)$ compared with infants who were fed control formulas $(\mathbf{O} ; n=10)(p<0.05)$. seems to result in increased bone mineralization (25-27). Short-term feeding of postdischarge formula to $2 \mathrm{mo}$ is not associated with changes in fat and lean body mass (28). This is the first study to report effects of DHA and ARA in formula on body composition in preterm infants. Although there were no effects on bone mineral deposition, infants who were fed the DHA+ARA-supplemented formulas from first enteral feedings to 12 mo CA had greater lean body mass and reduced fat mass at $12 \mathrm{mo}$.

Preterm infants who are fed formula during the early postnatal period accumulate fat faster than fetuses of similar postconceptional age (29). It has been suggested that dietary practices after hospital discharge have an even greater impact on body composition than dietary practices in-hospital (30). However, there is a paucity of data regarding the effect of the postdischarge diet on body composition in preterm infants. Ryan et al. (20) reported lower fat-free mass in preterm male infants who were fed preterm formula supplemented with $0.2 \%$ DHA but no ARA until 43 wk postmenstrual age followed by term formula that was similarly supplemented with DHA until 4.5 mo CA. By contrast, preterm infants in the present study who were fed formulas with both DHA+ARA, regardless of source, to 12 mo CA had more lean body mass (average LS mean difference, $300-470 \mathrm{~g}$ ), less fat mass (average LS mean difference, $470 \mathrm{~g}$ ), and no differences in overall weight than the control group. Fat mass values at 12 mo $\mathrm{CA}$ for the DHA+ARA-supplemented groups in the present study are in agreement with those reported by Butte et al. (31). Average fat mass at 12 mo for a group of 76 healthy infants who were either breast fed or fed infant formula was $2.59 \mathrm{~kg}$ (31). The control group fat mass values at 12 mo CA in the present study are higher than the Butte (31) reference group. The 470-g difference in fat mass between the supplemented groups and the control group observed in the present study represents a 5\% difference in total average body weight and, assuming that fat is $25 \%$ of total weight (31), a $20 \%$ difference in fat mass. The differences observed are within the specificity of DEXA, especially because DEXA becomes more precise as the total amount of fat mass exceeds $250 \mathrm{~g}$ (18).

When considering animal (12,32-37) and infant (20) studies that have examined body composition, the increase in lean body mass and corresponding reduced fat mass in the preterm 
infants in the present study were not anticipated. In studies with rodents, diets rich in the long-chain n-3 fatty acids DHA and EPA from fish oil have been associated with lower body fat when compared with diets rich in saturated fat (e.g. lard, medium chain triglyceride oil) or polyunsaturated fatty acids such as linoleic acid (e.g. corn oil) (12,32-37). Adult rats that were fed diets rich in DHA and EPA had preferential partitioning of ingested energy toward oxidation at the expense of storage (32), reduced fat mass (33), decreased fat cell trophic growth (34), altered expression of genes involved in adipose tissue metabolism (12) including lipoprotein lipase activity (36), increased peroxisomal $\beta$-oxidation (35), reduced adipocyte cell volumes (37), increased visceral fat hypertrophy (13), and altered regulation of leptin (38). These studies, however, did not examine diets rich in ARA to evaluate possible interactions between high dietary DHA and EPA and dietary ARA. In addition, >25- and 150-fold greater amounts of DHA and EPA, respectively, were fed in the rodent studies than in the present and other (20) infant formula studies that have examined body composition. In the study by Ryan et al. (20), preterm infants were fed formulas with DHA and EPA at $<0.3 \%$ of calories for $\sim 5$ mo after hospital discharge. Infants who were fed the supplemented formulas grew slower and had lower fat-free mass, but fat mass was not different from that in infants who were fed the unsupplemented control formula. Conversely, growth is not slower in preterm infants who are fed formulas that contain both ARA and DHA compared with an unsupplemented control formula (8,39-41), and as shown in the present study, lean body mass is greater and fat mass is reduced. Additional studies are needed to understand the specific effects of ARA and the long-chain n-3 fatty acids DHA and EPA on lean body mass and fat mass in infancy.

Preterm infants often experience postnatal growth restriction and have anthropometric measurements at $<10$ th percentile at the time of hospital discharge (42). They are also at risk for poor growth into childhood (43). Little is known about how postnatal growth patterns influence the body composition of very low birth weight, preterm infants. The present study suggests that feeding low birth weight infants during the first year of life with preterm formulas that are supplemented with DHA and ARA results in a body composition in which total fat mass is reduced and lean body mass is enhanced.

In the present study, neither bone mineral content nor bone mineral density was different between $35 \mathrm{wk}$ and $12 \mathrm{mo}$ CA in preterm infants who were fed either unsupplemented preterm formulas or preterm formulas that were supplemented with DHA and ARA for the first year of life. Consistent with these findings, Martinez et al. (7) reported that supplementation of preterm formula with ARA and DHA caused no disturbances in mineral balance. Studies with rodents $(14,44)$, piglets $(45)$, and chicks $(46,47)$, however, have reported effects of n-6 fatty acids (linoleic acid and ARA) and n-3 fatty acids (EPA and DHA) on bone formation. ARA (n-6) and EPA (n-3) are precursors to eicosanoids that influence the differentiation and activation of cells in bone and cartilage tissue. For example, in a study with formula-fed piglets, ARA and prostaglandin E2 (PGE2), synthesized from ARA, both increased bone mass, apparently by independent, distinct mechanisms (45). Others report concentration-dependent effects of PGE2 with higher levels associated with depressed bone formation $(13,47)$. Another study with formula-fed piglets reported that higher plasma DHA was associated with less bone resorption (48). Watkins et al. (46), however, reported that chicks that were fed diets rich in n-6 fatty acids led to increased levels of PGE2 and depressed bone formation rates compared with animals that were fed diets high in n-3 fatty acids. It is not known whether different levels or ratios of ARA, EPA, and DHA than those fed in the present study may affect bone formation in preterm infants. Further studies are warranted given the rapid bone remodeling that occurs during the first year of life in preterm infants (49). The results of the present study suggest that DHAand ARA-supplemented infant formulas can be fed to preterm infants for their neurodevelopment and visual acuity advantages without negative affects on bone mineralization.

The growth results of the present study are in agreement with those of the larger study of O'Connor et al. (4) with 470 preterm infants who were given the identical formulas used in the present study and fed for the same period of time. O'Connor et al. (4) found no consistent differences among the groups in weight, length, or head circumference. In several early studies, growth was restricted in preterm infants who were fed formulas that were supplemented with only n-3 fatty acids, as DHA alone or in combination with EPA, and no ARA (n-6 fatty acids) (20,50,51). In most studies in which preterm and term infants were fed formulas that were supplemented with both n-6 (ARA) and n-3 (DHA) fatty acids and little or no EPA, no adverse effects on growth were reported (8,39-41). Innis et al. (6) reported that infants who were fed preterm formula that was supplemented with DHA and ARA gained weight significantly faster than infants who were fed a standard unsupplemented preterm formula. Longitudinal growth was affected in one study that was designed to evaluate the neurodevelopmental outcome of preterm infants who were fed preterm formulas with and without DHA and ARA (9). The infants who were fed DHA- and ARA-supplemented preterm formula were $1.5 \mathrm{~cm}$ shorter at $18 \mathrm{mo}$ CA than infants who were fed an unsupplemented control preterm formula (9). The supplemented formula was fed for 3-4 wk, compared with 12-14 mo in the present study, and contained lower concentrations and different ratios of DHA and ARA than the study products used in the present study. Taken together, the growth data from this study and from previous reports suggest that preterm and discharge formulas that are supplemented with DHA and ARA support adequate growth of preterm infants.

\section{CONCLUSION}

No differences in growth or bone mineralization between 35 wk and 12 mo CA were found in preterm infants who were fed an unsupplemented control formula and those who were fed formulas that were supplemented with $0.16-0.26 \mathrm{wt} \%$ DHA and 0.41-0.43 wt\% ARA from combinations of either FF or EF. The most significant finding was that supplementation with DHA and ARA at the levels studied led to increased lean body mass and reduced fat mass at $12 \mathrm{mo} C A$. The long-term effects of DHA and ARA supplementation on body composition in both preterm and term infants deserve further study. 
Acknowledgments. This work was completed in partial fulfillment of the requirements for the degree of Doctor of Philosophy, Case Western Reserve University, Cleveland, $\mathrm{OH}$ (S.G.-W). The contributions of Patrick M. Catalano, M.D., and Isabel M. Parraga, Ph.D., RD, are gratefully acknowledged. We thank the staffs of the neonatal intensive care unit, the GCRC, and the Department of Radiology at MetroHealth Medical Center (Cleveland, $\mathrm{OH}$ ) as well as the parents who allowed their infants to participate. We also thank Jane Carver for expert assistance in the preparation of the manuscript.

\section{REFERENCES}

1. Innis SM 2003 Perinatal biochemistry and physiology of long-chain polyunsaturated fatty acids. J Pediatr 143:S1-S8

2. Carlson SE, Neuringer M 1999 Polyunsaturated fatty acid status and neurodevelopment: a summary and critical analysis of the literature. Lipids 34:171-178

3. Innis SM 2000 The role of dietary n-6 and n-3 fatty acids in the developing brain. Dev Neurosci 22:474-480

4. O'Connor DL, Hall R, Adamkin D, Auestad N, Castillo M, Connor WE, Connor SL, Fitzgerald K, Groh-Wargo S, Hartmann EE, Jacobs J, Janowsky J, Lucas A, Margeson D, Mena P, Neuringer M, Nesin M, Singer L, Stephenson T, Szabo J, Zemon V; Ross Preterm Lipid Study 2001 Growth and development in preterm infants fed long-chain polyunsaturated fatty acids: a prospective, randomized controlled trial. Pediatrics 108:359-371

5. SanGiovanni JP, Berkey CS, Dwyer JT, Colditz GA 2000 Dietary essential fatty acids, long-chain polyunsaturated fatty acids, and visual resolution acuity in healthy fullterm infants: a systematic review. Early Hum Dev 57:165-188

6. Innis SM, Adamkin DH, Hall RT, Kalhan SC, Lair C, Lim M, Stevens DC, Twist PF, Diersen-Schade DA, Harris CL, Merkel KL, Hansen JW 2002 Docosahexaenoic acid and arachidonic acid enhance growth with no adverse effects in preterm infants fed formula. J Pediatr 140:547-554

7. Martinez FE, Sieber VM, Jorge SM, Ferlin ML, Mussi-Pinhata MM 2002 Effect of supplementation of preterm formula with long chain polyunsaturated fatty acids on mineral balance in preterm infants. J Pediatr Gastroenterol Nutr 35:503-507

8. Vanderhoof J, Gross S, Hegyi T 2000 A multicenter long-term safety and efficacy trial of preterm formula supplemented with long-chain polyunsaturated fatty acids. J Pediatr Gastroenterol Nutr 31:121-127

9. Fewtrell MS, Morley R, Abbott RA, Singhal A, Isaacs EB, Stephenson T, MacFadyen U, Lucas A 2002 Double-blind, randomized trial of long-chain polyunsaturated fatty acid supplementation in formula fed to preterm infants. Pediatrics 110:73-82

10. Watkins BA, Lippman HE, Le Bouteiller L, Li Y, Seifert MF 2001 Bioactive fatty acids: role in bone biology and bone cell function. Prog Lipid Res 40:125-148

11. Peyron-Caso E, Quignard-Boulange A, Laromiguiere M, Feing-Kwong-Chan S, Veronese A, Ardouin B, Slama G, Rizkalla SW 2003 Dietary fish oil increases lipid mobilization but does not decrease lipid storage-related enzyme activities in adipose tissue of insulin-resistant, sucrose-fed rats. J Nutr 133:2239-2243

12. Raclot T, Groscolas R, Langin D, Ferre P 1997 Site-specific regulation of gene expression by $\mathrm{n}-3$ polyunsaturated fatty acids in rat white adipose tissues. J Lipid Res 38:1963-1972

13. Raisz LG 1993 Bone cell biology: new approaches and unanswered questions. J Bone Miner Res 8:S457-S465

14. Watkins BA, Li Y, Lippman HE, Feng S 2003 Modulatory effect of omega-3 polyunsaturated fatty acids on osteoblast function and bone metabolism. Prostaglandins Leukot Essent Fatty Acids 68:387-398

15. Papile LA, Burstein J, Burstein R, Koffler H 1978 Incidence and evolution of subependymal and intraventricular hemorrhage: a study of infants with birth weights less than $1500 \mathrm{gm}$. J Pediatr 92:529-534

16. Lohman TG, Roche AF, Martorell R 1991 Anthropometric Standardization Reference Manual (Abridged Edition). Human Kinetics Books, Champaign, IL, pp 3-41

17. Koo WW, Massom LR, Walters J 1995 Validation of accuracy and precision of dual energy x-ray absorptiometry for infants. J Bone Miner Res 10:1111-1115

18. Picaud JC, Rigo J, Nyamugabo K, Milet J, Senterre J 1996 Evaluation of dual-energy $\mathrm{X}$-ray absorptiometry for body composition assessment in piglets and term human neonates. Am J Clin Nutr 63:157-163

19. Association for Official Agricultural Chemists 2003 Official Methods of Analysis. Association for Official Agricultural Chemists, Arlington, VA, pp 28.082-28.085

20. Ryan AS, Montalto MB, Groh-Wargo S, Mimouni F, Sentipal-Walerius J, Doyle J, Siegman JS, Thomas AJ 1999 Effect of DHA-containing formula on growth of preterm infants to 59 weeks postmenstrual age. Am J Hum Biol 11:457-467

21. Carver JD, Wu PY, Hall RT, Ziegler EE, Sosa R, Jacobs J, Baggs G, Auestad N, Lloyd B 2001 Growth of preterm infants fed nutrient-enriched or term formula after hospital discharge. Pediatrics 107:683-689

22. Cooke RJ, Embleton ND, Griffin IJ, Wells JC, McCormick KP 2001 Feeding preterm infants after hospital discharge: growth and development at 18 months of age. Pediatr Res 49:719-722

23. Lucas A, Fewtrell MS, Morley R, Singhal A, Abbott RA, Isaacs E, Stephenson T, MacFadyen UM, Clements H 2001 Randomized trial of nutrient-enriched formul versus standard formula for postdischarge preterm infants. Pediatrics 108:703-711
24. Rajaram S, Carlson SE, Koo WW, Braselton WE 1995 Plasma mineral concentrations in preterm infants fed a nutrient-enriched formula after hospital discharge (part 1). J Pediatr 126:791-796

25. Bishop NJ, King FJ, Lucas A 1993 Increased bone mineral content of preterm infants fed with a nutrient enriched formula after discharge from hospital. Arch Dis Child 68:573-578

26. Brunton JA, Saigal S, Atkinson SA 1998 Growth and body composition in infants with bronchopulmonary dysplasia up to 3 months corrected age: a randomized trial of a high-energy nutrient-enriched formula fed after hospital discharge. J Pediatr 133:340-345

27. Cooke RJ, McCormick K, Griffin IJ, Embleton N, Falukner K, Wells JC, Rawlings DC 1999 Feeding preterm infants after hospital discharge: effect of diet on body composition. Pediatr Res 46:461-464

28. DeCurtis M, Pieltain C, Rigo J 2002 Body composition in preterm infants fed standard term or enriched formula after hospital discharge. Eur J Nutr 41:177-182

29. Reichman B, Chessex P, Putet G, Verellen G, Smith JM, Heim T, Swyer PR 1981 Diet, fat accretion, and growth in premature infants. N Engl J Med 305:1495-1500

30. Wauben IP, Atkinson SA, Shah JK, Paes B 1998 Growth and body composition of preterm infants: influence of nutrient fortification of mother's milk in hospital and breastfeeding post-hospital discharge. Acta Paediatr 87:780-785

31. Butte NF, Hopkinson JM, Wong WW, Smith EO, Ellis KJ 2000 Body composition during the first 2 years of life: an updated reference. Pediatr Res 47:578-585

32. Raclot T, Oudart H 1999 Selectivity of fatty acids on lipid metabolism and gene expression. Proc Nutr Soc 58:633-646

33. Hill JO, Peters JC, Lin D, Yakuba F, Greene H, Swift L 1993 Lipid accumulation and body fat distribution is influenced by type of dietary fat fed to rats. Int J Obes Relat Metab Disord 17:223-236

34. Parrish CC, Pathy DA, Angel A 1990 Dietary fish oils limit adipose tissue hypertrophy in rats. Metabolism 39:217-219

35. Halvorsen B, Rustan AC, Madsen L, Reseland J, Berge RK, Sletnes P, Christiansen EN 2001 Effects of long-chain monounsaturated and n-3 fatty acids on fatty acid oxidation and lipid composition in rats. Ann Nutr Metab 45:30-37

36. Benhizia F, Hainault I, Serougne C, Lagrange D, Hajduch E, Guichard C, Malewiak MI, Quignard-Boulange A, Lavau M, Griglio S 1994 Effects of a fish oil-lard diet on rat plasma lipoproteins, liver FAS, and lipolytic enzymes. Am J Physiol 267:E975-E982

37. Rustan AC, Hustvedt BE, Drevon CA 1998 Postprandial decrease in plasma unesterified fatty acids during n-3 fatty acid feeding is not caused by accumulation of fatty acids in adipose tissue. Biochim Biophys Acta 1390:245-257

38. Peyron-Caso E, Taverna M, Guerre-Millo M, Veronese A, Pacher N, Slama G, Rizkalla SW 2002 Dietary (n-3) polyunsaturated fatty acids up-regulate plasma leptin in insulin-resistant rats. J Nutr 132:2235-2240

39. Clandinin MT, Van Aerde JE, Parrott A, Field CJ, Euler AR, Lien EL 1997 Assessment of the efficacious dose of arachidonic and docosahexaenoic acids in preterm infant formulas: fatty acid composition of erythrocyte membrane lipids. Pediatr Res 42:819-825

40. Vanderhoof J, Gross S, Hegyi T, Clandinin T, Porcelli P, DeCristofaro J, Rhodes T, Tsang R, Shattuck K, Cowett R, Adamkin D, McCarton C, Heird W, Hook-Morris B, Pereira G, Chan G, Van Aerde J, Boyle F, Pramuk K, Euler A, Lien EL 1999 Evaluation of a long-chain polyunsaturated fatty acid supplemented formula on growth, tolerance, and plasma lipids in preterm infants up to 48 weeks postconceptional age. J Pediatr Gastroenterol Nutr 29:318-326

41. Uauy R, Hoffman DR, Birch EE, Birch DG, Jameson DM, Tyson J 1994 Safety and efficacy of omega-3 fatty acids in the nutrition of very low birth weight infants: soy oil and marine oil supplementation of formula. J Pediatr 124:612-620

42. Lemons JA, Bauer CR, Oh W, Korones SB, Papile LA, Stoll BJ, Verter J, Temprosa M, Wright LL, Ehrenkranz RA, Fanaroff AA, Stark A, Carlo W, Tyson JE, Donovan EF, Shankaran S, Stevenson DK 2001 Very low birth weight outcomes of the National Institute of Child Health and Human Development Neonatal Research Network, January 1995 through December 1996. NICHD Neonatal Research Network. Pediatrics 107:E1

43. Casey PH, Kraemer HC, Bernbaum J, Yogman MW, Sells JC 1991 Growth status and growth rates of a varied sample of low birth weight, preterm infants: a longitudinal cohort from birth to three years of age. J Pediatr 119:599-605

44. Sirois I, Cheung AM, Ward WE 2003 Biomechanical bone strength and bone mass in young male and female rats fed a fish oil diet. Prostaglandins Leukot Essent Fatty Acids 68:415-421

45. Lucia VD, Fitzpatrick-Wong SC, Weiler HA 2003 Dietary arachidonic acid suppresses bone turnover in contrast to low dosage exogenous prostaglandin $\mathrm{E}(2)$ that elevates bone formation in the piglet. Prostaglandins Leukot Essent Fatty Acids 68:407-413

46. Watkins BA, Shen CL, Allen KG, Seifert MF 1996 Dietary (n-3) and (n-6) polyunsaturates and acetylsalicylic acid alter ex vivo PGE2 biosynthesis, tissue IGF-I levels, and bone morphometry in chicks. J Bone Miner Res 11:1321-1332

47. Watkins BA, Shen CL, McMurtry JP, Xu H, Bain SD, Allen KG, Seifert MF 1997 Dietary lipids modulate bone prostaglandin E2 production, insulin-like growth factor-I concentration and formation rate in chicks. J Nutr 127:1084-1091

48. Weiler HA, Fitzpatrick-Wong S 2002 Dietary long-chain polyunsaturated fatty acids minimize dexamethasone-induced reductions in arachidonic acid status but not bone mineral content in piglets. Pediatr Res 51:282-289

49. Rigo J, De Curtis M, Pieltain C, Picaud JC, Salle BL, Senterre J 2000 Bone mineral metabolism in the micropremie. Clin Perinatol 27:147-170

50. Carlson SE, Cooke RJ, Werkman SH, Tolley EA 1992 First year growth of preterm infants fed standard compared to marine oil n-3 supplemented formula. Lipids 27:901-907

51. Carlson SE, Werkman SH, Tolley EA (1996) Effect of long-chain n-3 fatty acid supplementation on visual acuity and growth of preterm infants with and without bronchopulmonary dysplasia. Am J Clin Nutr 63:687-697 